\title{
Design, construction and testing of a low carbon thin-shell concrete flooring system
}

\author{
Will Hawkins*, John Orra ${ }^{\mathrm{a}}$, Paul Shepherd ${ }^{\mathrm{b}}$, Tim Ibell ${ }^{\mathrm{b}}$. \\ * Corresponding author \\ Department of Engineering, University of Cambridge \\ Trumpington St, Cambridge, UK \\ wjh35@cam.ac.uk \\ ${ }^{a}$ Department of Engineering, University of Cambridge \\ ${ }^{b}$ Department of Architecture and Civil Engineering, University of Bath
}




\begin{abstract}
Rapid global urbanisation and population growth is driving unprecedented levels of building construction, with the total worldwide floor area expected to almost double over the next 40 years. Since most of the structural material in a building exists within the floors, these present a significant opportunity for structural engineers to contribute to a more sustainable construction industry.

This paper examines a novel flooring system of textile-reinforced concrete shells with a foamed concrete fill, which has the potential to halve the amount of materials in a building's entire structure. A new design and geometry optimisation method is described, as well as the construction and testing of two prototypes; each $18 \mathrm{~mm}$ thick, $2 \mathrm{~m}$ in span and $200 \mathrm{~mm}$ tall. These textile-reinforced concrete shells are unconventional in their low total depth, low reinforcement content and lack of rigid supports. Both were reinforced with AR-glass fibre textile and constructed using fine-grained concrete, however only one featured a foamed concrete fill. Each was tested to destruction under an asymmetric load. In both cases, a hinged collapse mechanism was formed rather than sudden catastrophic failure, with positive implications for safety and robustness.

A non-linear finite element model was developed which replicated the observed behaviour well, including cracking patterns. Inaccuracies in geometry arising from the hand-made construction methods were measured and their structural impact was assessed and found to be small.
\end{abstract}

The investigations confirm the strength, robustness and buildability of the structural system, and establish a reliable analysis method.

Keywords: Sustainable construction; Concrete shells; Textile reinforced concrete; Structural testing; Shape optimisation.

\title{
1. Introduction
}

Driven by population growth and urbanisation, the total worldwide floor area of buildings is projected to double over the next 40 years, the equivalent of constructing Paris once every five days [1]. Building materials already make up the majority of global resource consumption [2], however at present building structures are often highly inefficient with material utilisation in the region of $50 \%$ being common $[3,4]$. This creates a huge and unnecessary environmental cost, particularly when combined with unrealistically high design loads [5]. Most of the 
embodied energy in a typical multi storey building is contained within the floors $[6,7]$, making these a primary target for reducing material consumption.

Steel reinforced concrete dominates multi-storey building construction. Global cement production has more than doubled since 2003, and in 2014 accounted for $5.8 \%$ of global $\mathrm{CO}_{2}$ emissions [8]. A common concrete flooring system is the flat slab, where the uniform thickness brings advantages of simple formwork assembly and removal, architectural flexibility and a low overall structural depth. Flat slabs are designed to resist load through shear and bending forces, and the strain distributions which arise mean that typically over half of the concrete is cracked; thus the majority of the material (and self-weight) makes little direct strength contribution.

In contrast, compressive forms such as vaults and shells resist load primarily through membrane forces. The absence of bending forces keeps stresses low and minimises cracking, leading to greatly improved material efficiency [9]. Ockleston [10] showed that the capacity of a flat slab can be five times higher than that predicted by an upper-bound yield line analysis due to an arching effect he named compressive membrane action, which occurs when lateral movement is restrained. This supports the notion that an alternative approach to concrete floors, designed with arching action in mind, could potentially provide significant material savings.

Concrete shells have a history of successful application for large span roofs and canopies, where foundations are stiff, self-weight is dominant and large curvatures are an architectural intent [9]. However, there are many further complexities to consider for a floor structure, not least the construction of a level top surface. Whilst it is possible in theory to design a compression only (funicular) shell geometry for a specific loading and support condition, bending forces will arise in practice due to variations in live loading, movement of supports and differential settlement of columns, as well as any errors in the manufactured geometry. Service openings, temporary loadcases and overall building stability also increase the design complexity. A shallow vault must be able to resist buckling whilst retaining a reasonable total structural depth, and some method of providing a level floor surface must be found. Crucially, the structure must be simple to construct and cost-effective. An important question therefore arises; can a vaulted floor meet these criteria whilst still providing meaningful savings in selfweight and embodied energy compared to traditional slab systems?

There is already a history of successful application of shell floors using Catalan tile-vaulting. For centuries, arches and vaults were the only way to create spanning structures using solid 
and durable (yet brittle) materials such as stone, brick and concrete. In the eighteenth century, light, shallow, singly curved tile vaults with a rubble fill spanning up to $7.5 \mathrm{~m}$ were being constructed in France, being favoured over timber floors for their fire resistance [11]. The sixstorey Versailles Library, constructed in 1762, is a notable example which still stands today. The technique of tile vaulting reached new levels of technical prowess with the structures of Raphael Guastavino, who constructed over 1000 tiled domes, vaults and floors across North America between 1890 and 1940 [12]. However, the reducing cost of steel, in the form of concrete reinforcement or off-the-shelf beam sections, led to compression vaults being largely replaced by beams and slabs in the mid to late $20^{\text {th }}$ century. Advances in concrete technology did, nevertheless, lead to some innovation in vaulted floors, including patented pre-cast systems by Tully [13], Leggatt [14] and Ramaswamy and Chetty [15], whose fabric-formed shells were used in thousands of buildings across India.

Today, advances in materials, manufacturing methods and computational techniques increasingly allow designers to explore and rediscover the structural advantages of non-planar geometries. Liew et al. [16] demonstrated the potential of digital form-finding and manufacturing in the creation of a lightweight rib stiffened vaulted floor structure, whilst West [17] and Orr et al. [3] have used fabric formwork to construct efficient concrete forms.

This paper examines one method to reduce the embodied energy of concrete floors through consideration of both structural form and materials, whilst also bearing in mind architectural performance and constructability. A system of pre-cast textile reinforced shells is proposed, and the design, optimisation, construction, structural testing, measurement and analysis of two prototypes is described.

\section{Background}

\subsection{Structural concept}

In the system proposed by the authors, pre-cast concrete shells span between column supports to create a vaulted ceiling as shown in Fig. 1. Using a shell without stiffeners simplifies the manufacturing process by allowing the use of single-sided formwork. Furthermore, services can be integrated within the structural depth, both above and below the shell, without obstruction. This frees up vertical space to maximise the rise of the shell, increasing efficiency. A self-levelling fill is applied in-situ to create a usable floor surface, using the shell as formwork. The structural requirement of the fill is only to transfer vertical loads to the shell, and therefore a low-density foamed concrete is proposed to minimise material use. Foamed 
concrete also provides good thermal and acoustic insulation [18], and has been used successfully in sandwich panel floors [19] and beams [20] in combination with normal weight concrete.

The imbalance of lateral thrust at the building's edges is balanced by a grid of steel ties spanning between columns. The stiffness of these ties affects the shell's performance since displacement of the supports causes bending. The ties can however be prestressed to minimise this effect, and to reduce the maximum vertical displacement. The proposed location of the ties is just below the interface between the shell and column, where the compressive and tensile forces from the arch and tie are aligned. The column thus experiences no bending force. In practice, the height of the ties could be adjusted from this location with the columns designed accordingly.

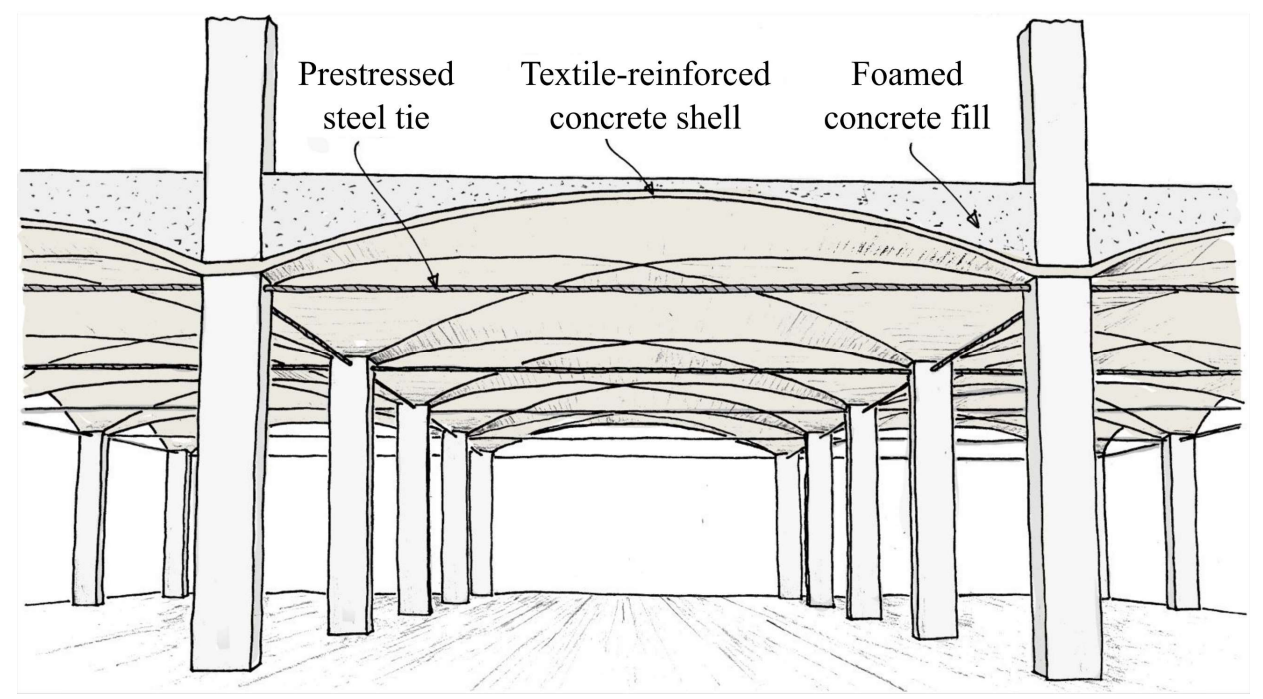

Fig. 1. Thin-shell vaulted floor concept sketch

Although the structural system is designed to act primarily in compression, reinforcement is required to increase tensile capacity and provide robustness in the event of accidental loading. Textile reinforced concrete (TRC) is therefore proposed. TRC is a composite material consisting of a fine-grained concrete with layers of fibre reinforcement in the form of an open orthogonal mesh [21]. The flexibility of the reinforcement allows the production of complex or freeform geometries, and the glass or carbon fibres typically used do not require additional concrete cover for durability, thus minimising the required shell thickness.

\subsection{Previous work}

A computational investigation was previously carried out to determine the feasibility of the proposed system and to compare the performance of a range of candidate shell geometries, as 
detailed in Hawkins et al. [22]. These included hyperbolic paraboloids (hypars) and groin vaults, whose formwork can be constructed using straight timber elements, as well as geometries form-found using dynamic relaxation and those which arise using a hanging woven fabric formwork. The parabolic groin vault was identified as having good structural performance despite its singly curved geometry. Although fabric formwork has advantages of construction simplicity and waste reduction, a timber-formed solution was found to create a shell geometry with lower self-weight and strain energy in this case.

A case study for a typical UK office building with $8 \mathrm{~m}$ spans was undertaken, demonstrating potential reductions in total embodied energy and self-weight of $62 \%$ and $64 \%$ respectively compared to an equivalent strength flat slab with a similar total depth (taking service integration into account). In practice, these weight savings will also reduce column and foundations loads, potentially halving the material requirements for a tall building.

Building on the results of these initial computational investigations, an experimental programme was devised to further investigate construction processes, materials and structural behaviour.

\section{Design}

Two test specimens were constructed, one with and one without foamed concrete fill (referred to as the 'unfilled' and 'filled' shells hereafter). Each shell and was square on plan and supported at each corner over a $2 \mathrm{~m}$ span.

Both prototypes were a quarter-scale representation of a typical application with $8 \mathrm{~m}$ spans in an office or residential building. The full-scale structural depth of $800 \mathrm{~mm}$ is equivalent to a $300 \mathrm{~mm}$ thick flat slab with $500 \mathrm{~mm}$ service zone, as considered in previous computational investigations [22]. The corner supports were $62.5 \mathrm{~mm}$ square, each representing a quarter of the area of a typical $500 \mathrm{~mm}$ square column at full scale. All dimensions were scaled proportionally whilst retaining the full-scale loadings, with additional loading applied to make up for the self-weight lost in the scaling process, and thus the stresses and materials remained representative of the full-scale structure. This section describes the design methodology developed to determine the geometry and thickness of the shell.

\subsection{Design criteria}

Loadings were chosen to simulate a typical design of an office building according to BS EN 1991-1-1 [23], with partial factors applied accordingly to both loads and material strengths. The design loadings included a live load of $3.50 \mathrm{kN} / \mathrm{m}^{2}$ and superimposed dead load 
of $1.00 \mathrm{kN} / \mathrm{m}^{2}$ with partial factors of 1.50 and 1.35 respectively. These factors were included to simulate the design of a real floor structure. A full-scale self-weight of $2.75 \mathrm{kN} / \mathrm{m}^{2}$ was assumed. The shells were therefore designed to support maximum (factored, dead and live) and minimum (unfactored, dead only) loadings of $10.31 \mathrm{kN} / \mathrm{m}^{2}$ and $3.75 \mathrm{kN} / \mathrm{m}^{2}$ respectively. Multiple patterns of live loading were considered by splitting the shell into quartile regions and considering each possible loading arrangement, as shown in Fig. 5.

A TRC section with a single top and bottom layer of alkali resistant (AR) glass fibre textile reinforcement (as described in Section 4.1) and a cover of $3 \mathrm{~mm}$ was selected based on preliminary experiments. For design purposes, the properties of the weaker (fill) textile reinforcement orientation (Table 1) were assumed in both directions to conservatively simplify the analysis and give flexibility of reinforcement layout for construction. The shells were designed prior to construction and testing of the specific shell concrete mixes (described in Section 4.2), requiring the concrete strength and stiffness to be assumed (as $32 \mathrm{MPa}$ and $33 \mathrm{GPa}$ respectively). Material partial factors of 1.5 were applied to both the concrete and textile strength, thus mirroring a typical ultimate limit state design approach.

\subsection{Groin vault optimisation}

The parabola used to describe the groin vault geometry in the previous computational investigation [22] was chosen because, theoretically, a parabolic arch carries a uniform floor

load in pure compression. Each of the four triangular segments of the groin vault might therefore be expected to act purely in compression. However, this scenario causes bending in the diagonal creases, which are also parabolic yet carry a linearly varying vertical load rather than a uniform one. A singly-curved groin-vaulted shell therefore does not have a pure compression form, and requires some bending capacity. The vault must also be able to withstand multiple patterns of live loading, each of which causing different distributions of axial and bending forces. The best shell geometry (that which minimises the material requirements, which in this case are the thickness of the shell and diameter of the tie rods) is therefore not obvious and must be found using a numerical process. The geometry of the shell was therefore parameterised to enable optimisation of the form.

The groin vault is defined by a two-dimensional curve, the start and end points of which are pre-determined by the span, column size, and total depth (Fig. 2). It is desirable to minimise the number of parameters to reduce complexity and computation time, however the curve definition must also be versatile enough to avoid leaving gaps in the design space. A Bézier 
curve was used with four control points defined by the half-span (L), rise $(\mathrm{H})$ and two nondimensional parameters a and $\mathrm{b}$. Despite using only two parameters, the curve was found to be able to match circular, catenary and parabolic test curves to within maximum deviations of $0.03 \mathrm{~mm}, 0.02 \mathrm{~mm}$ and $0.05 \mathrm{~mm}$ respectively; distances far lower than construction tolerance even after scaling back up to full size.

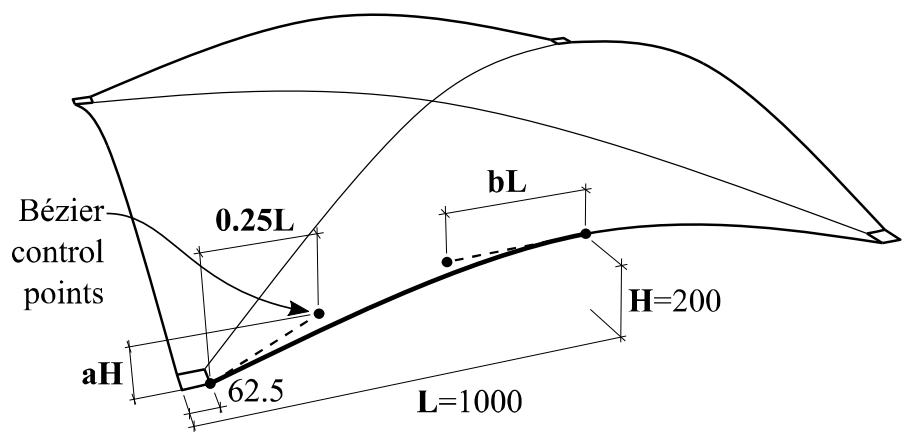

Fig. 2. Definition of singly-curved groin vault geometry using a Bézier curve with four control points and two non-dimensional parameters $a$ and $b$

The design procedure is shown in Fig. 3. Firstly, a candidate shell thickness and tie diameter were selected, along with initial values of $a, b$ and tie prestrain. The tie diameters were constrained to the available sizes of threaded rod to facilitate construction and prestressing. Structural analysis was performed using a linear finite element (FE) analysis in Karamba [24], an FE solver for the Grasshopper Rhino plug-in. In this model, the fill was ignored, and the corner supports were fixed vertically but allowed to slide (about the $\mathrm{x}$ and $\mathrm{y}$ axes) and rotate (about the $\mathrm{z}$ axis).

The geometric parameters (to three decimal places) and the pre-strain in the tie (to two decimal places in $\mathrm{mm} / \mathrm{m}$ ) were then optimised using the Galapagos evolutionary solver, part of the Grasshopper plug-in to Rhino [25]. The 'fitness' parameter minimised was the envelope of maximum bending strain energy, considering all live load patterns. A preliminary study showed that bending strain energy is a reliable proxy for the local strength utilisation in the shell (yielding similar optimal parameters), but it has the advantages of requiring fewer material assumptions and computational steps. An example of the fitness surface is shown in Fig. 4. The smooth variation of bending strain energy observed across the design space indicates that the optimisation routine finds the global rather than local optimum solution. The calculated axial and bending forces were combined to calculate the local strength utilisation based on a tri-linear failure envelope as described in Hawkins et al. [22]. The utilisation envelope was then inspected and the thickness and/or tie diameter modified if necessary, with 
the aim of creating an efficient design whilst avoiding over-utilisation of the shell at the design load.

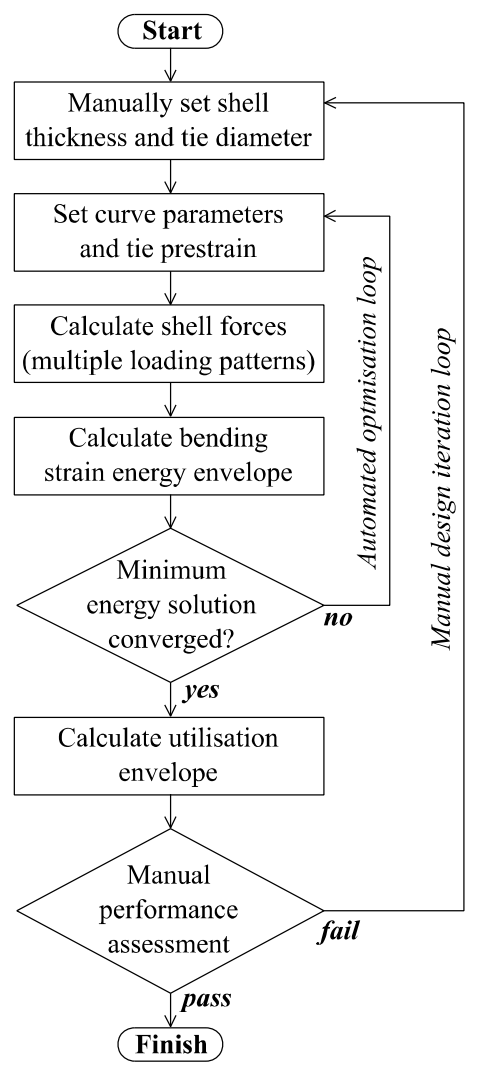

Fig. 3. Shell geometry design process

The final design thickness was $18 \mathrm{~mm}$, corresponding to assumed compressive, tensile and bending strengths of $384 \mathrm{kN} / \mathrm{m}, 92.3 \mathrm{kN} / \mathrm{m}$ and $0.494 \mathrm{kNm} / \mathrm{m}$ respectively. Tie rods of $14.1 \mathrm{~mm}^{2}$ cross-sectional area, equivalent to a $16 \mathrm{~mm}$ outer diameter threaded rod, were chosen. The optimal geometric parameters were found to be $a=0.385$ and $b=0.326$, with a tie pre-strain of $0.56 \mathrm{~mm} / \mathrm{m}$. With this optimised geometry, the total bending strain energy envelope was reduced by $9.8 \%$ compared to the starting parabolic profile. 


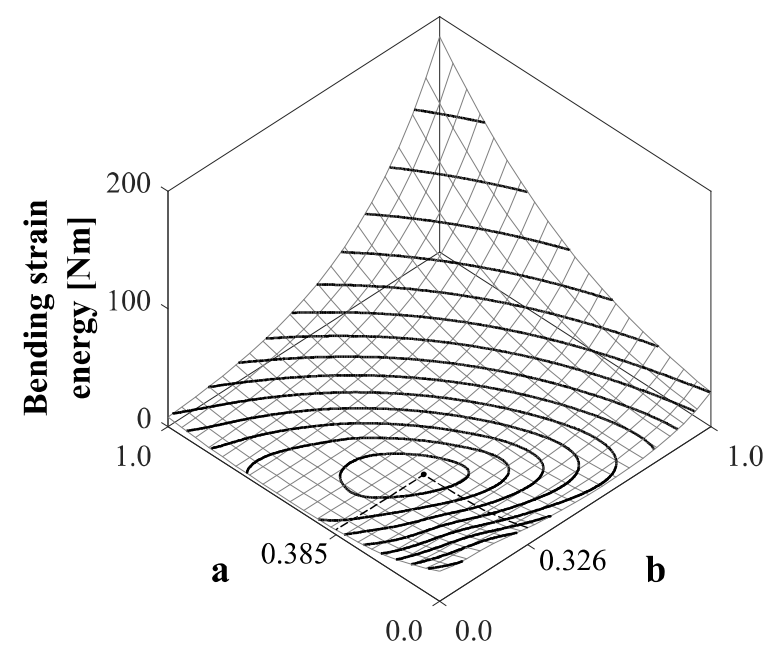

Fig. 4. Fitness surface showing smooth variation of the bending strain energy envelope with the geometric parameters $a$ and $b$ for a shell thickness of $18 \mathrm{~mm}$, with ties of $14.1 \mathrm{~mm}$ diameter and a prestrain of $0.56 \mathrm{~mm} / \mathrm{m}$. Contour lines are spaced logarithmically for clarity.

\subsection{Critical live loading pattern}

Each live load pattern was also analysed individually for the final design in order to determine the critical loading for testing. Fig. 5 compares the distribution of utilisation across the shell for each live load pattern at the design load. The cumulative distribution (Fig. 5, right) shows that live loading applied over one half of the shell only (pattern C) gives the greatest areas of high utilisation. This critical loading pattern was therefore chosen for testing the specimens to failure. For each load case, a small number of elements near the corner supports showed a utilisation greater than 1.00. Stress concentrations in these locations lead to local peaks in compressive stress and bending forces, however in the real structure some degree of redistribution is likely to occur. In load pattern $\mathrm{C}$, areas of high utilisation can also be seen over the central parts of the shell. These correspond to regions of sagging and hogging moments, with predicted tensile stresses indicating possible crack formation.

An additional, geometrically non-linear, analysis showed factors of safety of over 20 for buckling for each load pattern at the design loading, with the effects of cracking ignored.

The predicted mode of failure under load pattern $\mathrm{C}$ is therefore not immediately clear from this initial investigation, although a number of possibilities can be proposed: local compressive failure at one or more supports, local bending failure across the middle of the shell, global instability caused by the onset of cracking or finally the formation of a hinged collapse mechanism. 

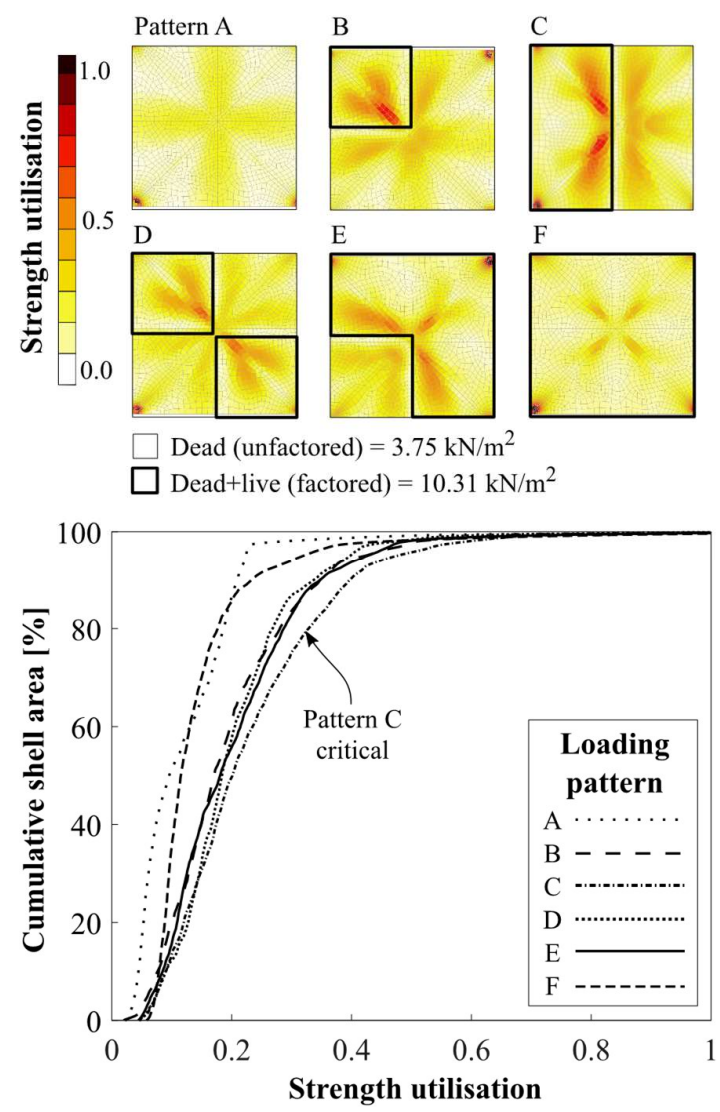

Fig. 5. Distribution of utilisation across the shell at the design loading for each live loading pattern, with live loads outlined in bold. Both the spatial and cumulative utilisation distributions are shown, and indicate that pattern $\mathrm{C}$ is the most likely to cause failure.

\section{Materials}

\subsection{Textile reinforcement}

The reinforcement used was an alkali-resistant (AR) glass fibre mesh with epoxy resin coating. This textile was chosen for its strength and flexibility, as well as its low cost compared to carbon fibres, the other most commonly used material for TRC. Glass fibres also have an embodied energy around ten times lower than carbon [26]. The properties of the reinforcement material were determined through tensile tests on individual yarns, described in detail in Hawkins et al. [27]. The material is linear-elastic, and has the mechanical properties shown in Table 1. Due to variations in yarn spacing and construction the material was found to have different effective strength and stiffnesses in the warp and fill directions. The tensile strength of the reinforcement is reduced when embedded in concrete as part of a composite TRC section, since bonding of the outer fibres with the concrete and cracking leads to local stress concentrations [28]. For glass fibres, some loss of strength over time may also be expected due 
to the alkalinity of the surrounding environment [29, 30]. Tensile tests, similar to those described in Hawkins et al. [27], were therefore carried out on $18 \mathrm{~mm}$ thick TRC specimens cast and tested alongside each shell to determine the composite strength of the reinforcement $f_{t c}$.

Table 1. AR-glass fibre reinforcing mesh properties

\begin{tabular}{r|cccc} 
& Warp & Fill \\
Strength, $f_{t}[\mathrm{MPa}]$ & 1192 & 1326 \\
Composite strength, $f_{t c}[\mathrm{MPa}]$ & 813 & 774 \\
Stiffness, $E_{t}[\mathrm{GPa}]$ & 64.0 & 55.7 \\
Yarn weight $[\mathrm{g} / \mathrm{m}]$ & 1.41 & 1.41 \\
Yarn spacing $[\mathrm{mm}]$ & 8 & 10 \\
Area, $A_{t}\left[\mathrm{~mm}^{2} / \mathrm{m}\right]$ & 65.3 & 52.2
\end{tabular}

\subsection{Fine-grained concrete}

A fine-grained concrete mix was developed with the aim of achieving good workability for the formation of $3 \mathrm{~mm}$ thick layers by hand, and a target compressive strength of approximately 32GPa. This was layered with the reinforcement to create a composite TRC section.

For both shells, the binder consisted of $70 \%$ Portland cement and 30\% fly ash (conforming to British Standards [31]). Minimising the Portland cement content and replacing with pozzolanic binders decreases the embodied energy as well as improving the durability of glass-fibre reinforcement by lowering alkalinity [29]. Lignin-based plasticiser was included at $2 \mathrm{ml}$ per kilogram of binder. The aggregate/binder ratio was 2 . The maximum aggregate size was $2 \mathrm{~mm}$, allowing the construction of cover layers of $3 \mathrm{~mm}$ thickness. The natural particle size distribution of the aggregate was modified to maximise the concrete strength by reducing the proportion of $0-1 \mathrm{~mm}$ particles from the natural value of $75 \%$ to $50 \%$.

Similar concrete mix proportions were used for both the filled and unfilled shells, apart from the water/cement ratio. Since the concrete was spread by hand trowelling onto an inclined surface, it was important to achieve an optimum workability. Water was added to each mix until this was achieved, which resulted in water/cement ratios of 0.41 for the unfilled shell and 0.45 for the filled shell. This difference was likely a result of natural variations in the aggregate used and/or atmospheric conditions, and led to differences in density between the two batches. Table 2 shows the concrete mix proportions for each shell. 
Four $100 \mathrm{~mm}$ cubes were cast and tested (at an age of 14 days) along with each of the two shells. The average strengths were $35.5 \mathrm{MPa}$ and $39.0 \mathrm{MPa}$ for the unfilled and filled shells respectively. The higher strength of the concrete used for the filled shell is a result of the lower water/cement ratio. The same cubes were also used to calculate the densities given in Table 2 . Fine-grained concrete used for TRC has often been shown to have a considerably lower stiffness than regular concrete of similar strength [32, 33]. Six 160x40x40mm prisms were therefore tested in compression to investigate the stress-strain behaviour of the material. The results closely matched the parabolic stress-strain model given in BS EN 1992-1-1 (Equation 3.14) [34], albeit with a stiffness $16 \%$ lower than expected of a concrete with similar strength.

Table 2. Constituents of fine-grained concrete mixes used in the construction of each TRC shell

\begin{tabular}{rcc} 
& $\begin{array}{c}\text { Unfilled } \\
\text { shell }\end{array}$ & $\begin{array}{c}\text { Filled } \\
\text { shell }\end{array}$ \\
\hline Dry density $\left[\mathrm{kg} / \mathrm{m}^{3}\right]$ & 2081 & 2175 \\
Portland cement $\left[\mathrm{kg} / \mathrm{m}^{3}\right]$ & 422 & 446 \\
Fly ash $\left[\mathrm{kg} / \mathrm{m}^{3}\right]$ & 181 & 191 \\
Aggregate $(0-1 \mathrm{~mm})\left[\mathrm{kg} / \mathrm{m}^{3}\right]$ & 603 & 637 \\
Aggregate $(1-2 \mathrm{~mm})\left[\mathrm{kg} / \mathrm{m}^{3}\right]$ & 603 & 637 \\
Water $\left[\mathrm{kg} / \mathrm{m}^{3}\right]$ & 271 & 261 \\
Plasticiser $\left[\mathrm{ml} / \mathrm{m}^{3}\right]$ & 1206 & 1275
\end{tabular}

\subsection{Foamed concrete}

Foamed concrete was cast in-situ on top of the second (filled) shell specimen, creating the flat top surface as proposed in the full-scale system. A foamed concrete mix was designed with the aims of minimising weight and material use whilst providing sufficient strength and robustness for the structural tests. A target compressive strength of $1.0 \mathrm{MPa}$ and dry density of $800 \mathrm{~kg} / \mathrm{m}^{3}$ were established in preliminary testing.

The foamed concrete was created by first mixing a mortar paste, consisting of sand (with particle size below $1 \mathrm{~mm}$ ), binder (a CEMII/B blend of Portland cement and fly ash) and water. The sand/cement ratio was 1.0 , water/cement ratio 0.5 , and $2 \mathrm{ml}$ of lignin plasticiser was included per $\mathrm{kg}$ of binder. Foam was created separately in batches by aerating a mixture of water and a foaming agent [35] using a power drill with a mixer attachment. Approximately 
$6001 / \mathrm{m}^{3}$ of foam was then added to the mortar and mixed, with density of the mix measured prior to casting.

The foamed concrete was cast five days after construction of the filled shell. Four 100mm cubes were cast simultaneously and tested at an age of nine days, coinciding with the main shell tests. The average wet and dry densities of these cubes were $844 \mathrm{~kg} / \mathrm{m}^{3}$ and $805 \mathrm{~kg} / \mathrm{m}^{3}$ respectively. Each cube was tested in compression between steel plates, and the load and displacement measured. Initially linear-elastic behaviour was observed followed by a plateau during which crushing took place, as is typical for brittle-elastic closed-cell foams [36]. The average stiffness in the elastic region was $0.238 \mathrm{GPa}$. The average stress at first crushing was $0.83 \mathrm{MPa}$. At a strain of $3 \%$, the average stress had dropped to $0.62 \mathrm{MPa}$. This remained approximately constant as the strain was increased beyond $4 \%$.

\section{Construction}

The single curvature of the groin vault allowed formwork to be constructed from sheets of plywood, with timber stiffeners, as shown in Fig. 6. The same formwork was used for both shells, with the unfilled shell being constructed (and tested) first.

The formwork was first levelled using screw jacks and a release agent applied. The steel corner supports were then positioned. The three layers of fine-grained concrete were applied by hand using steel trowels. The target layer thicknesses of $3 \mathrm{~mm}, 12 \mathrm{~mm}$ and $3 \mathrm{~mm}$ (totalling $18 \mathrm{~mm}$ ) were monitored during construction using guides on the formwork, spirit levels and spot checks. The concrete was also weighed out before applying to each segment to assist in the creation of an accurate average thickness. Each of the two reinforcement layers consisted of four triangular segments, each overlapping by $50 \mathrm{~mm}$ to ensure transfer of load, as shown in Fig. 6. The warp direction was aligned parallel with the formwork edges due to the $1 \mathrm{~m}$ width of the roll in the fill direction. 

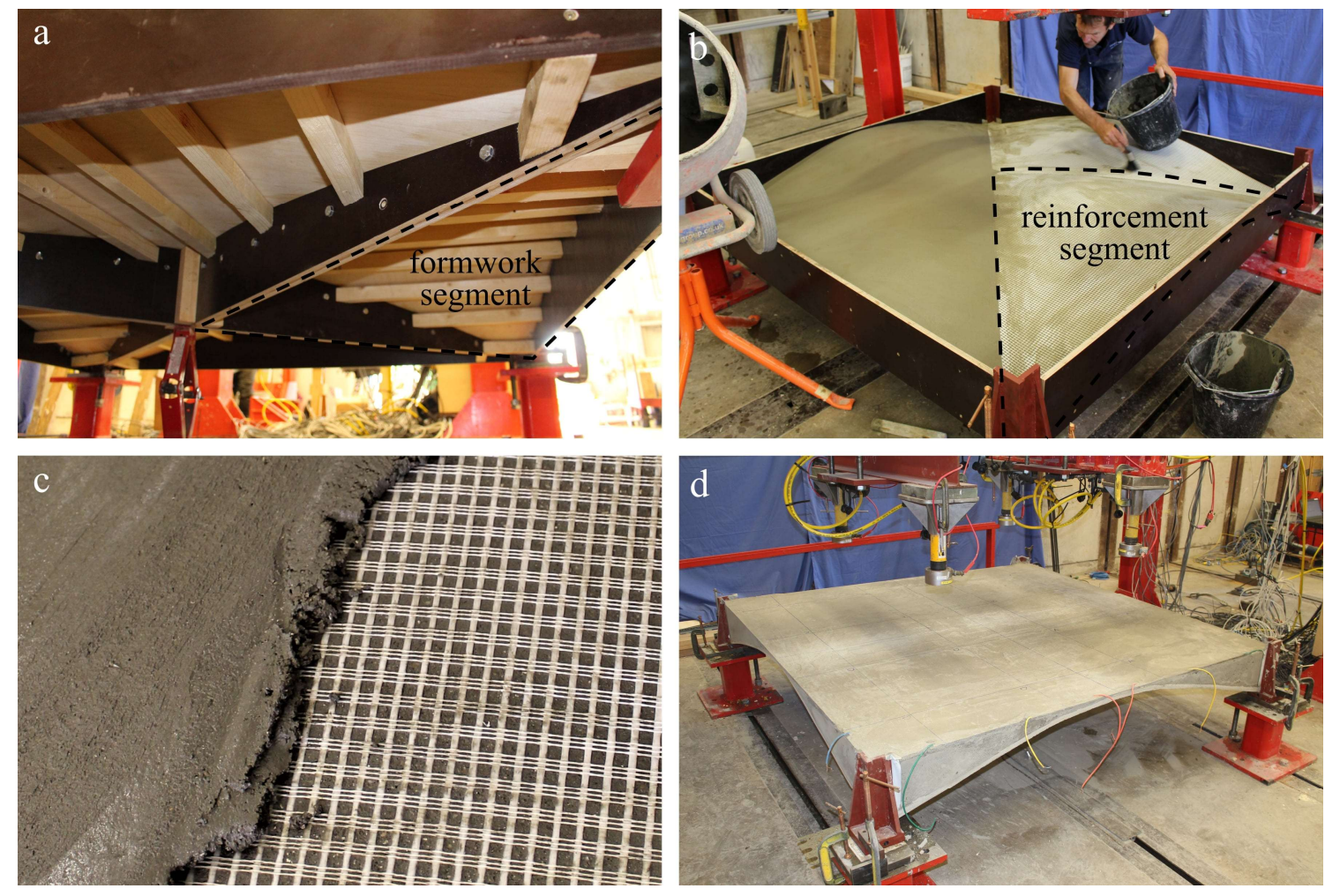

Fig. 6. Construction of TRC shells, showing a) segmental plywood formwork, b) application of the AR-glass textile reinforcement, c) close-up of mortar and reinforcement and d) a completed shell with foamed concrete fill and formwork removed

For the filled shell, the foamed concrete was cast onto the finished TRC with the formwork still in place. After removal of the formwork, the threaded steel tie rods were inserted through the bases of the corner supports and secured in place. Each tie was fixed into one support but free to slide through the other, thus allowing pre-strain to be applied through tightening of a nut, measured by its angle of rotation.

\section{Test methodology}

Loading was applied using four hydraulic jacks, each distributed to four $200 \mathrm{~mm}$ square loading patches via a loading spreader assembly, shown in Fig. 7. These were fully articulated using a system of pins and ball joints in order to distribute load as evenly as possible during deformation. Separate tests were performed on each of the four assemblies to verify this, by loading each assembly to $12 \mathrm{kN}$ cyclically and monitoring the load distribution with load cells under each patch. The results showed a standard deviation of $2.9 \%$ between patch loads while the supports were flat, rising to $4.6 \%$ with a differential elevation (on one patch) of $30 \mathrm{~mm}$. The loading was therefore assumed to be uniform during the tests. 
Each loading patch consisted of a steel plate levelled using dental plaster to a minimum depth of $30 \mathrm{~mm}$. For the unfilled shell, the loading patches nearest to the corners were levelled using a steel box section (Fig. 7, left). The four specimen corners and corresponding jacks were labelled A, B, C and D as shown in Fig. 8. Jacks A and B were controlled independently of jacks $\mathrm{C}$ and $\mathrm{D}$, thus allowing application of an asymmetric load.

The corner supports were constructed from steel plates, as shown in Fig. 7, each providing a $62.5 \mathrm{~mm}$ square horizontal support surface upon which the TRC was cast. These were supported on steel plinths (bolted to a strong floor) and set upon greased PTFE sheets to minimise horizontal friction (Fig. 7, right).

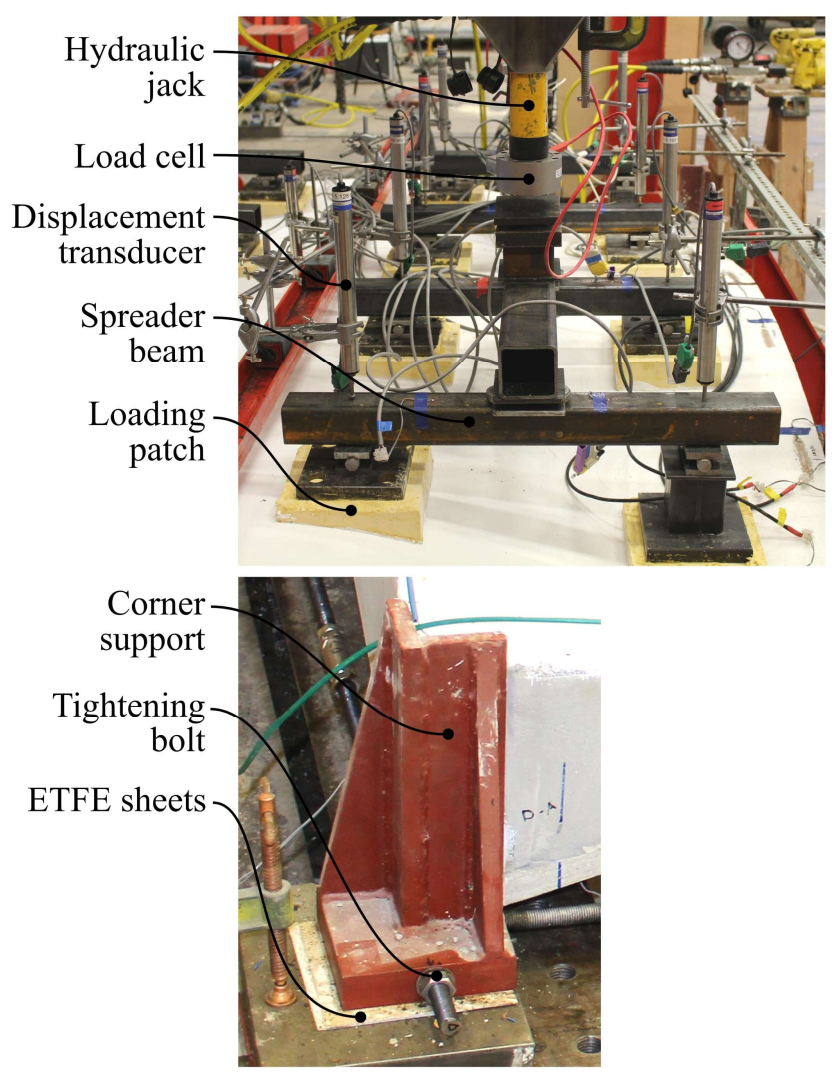

Fig. 7 Load spreader assembly and instrumentation (left) and corner support (right)

The tests were monitored with load cells, displacement transducers, and strain gauges at the locations shown in Fig. 8. Load cells were placed beneath each loading jack and were monitored in real-time to control the tests. Nine displacement transducers were located across the shell to measure the vertical deformation. Eight of these were centred above loading patches (on the load spreader steelwork) and one at the centre of the shell itself. Eight further transducers were used to measure horizontal displacements, placed in orthogonal pairs at the 
bases of each corner support. The extension of each tie could therefore be monitored using the difference of the displacement readings at each end. Strain gauges were attached in opposite pairs onto each tie rod. Separate tensile tests on each tie were conducted to determine the tie stiffness and to calibrate the tie force to the average strain. Finally, a total of sixteen concrete strain gauges (of $60 \mathrm{~m}$ length) were located on each shell in opposite top and bottom pairs. All data was logged at one second intervals.

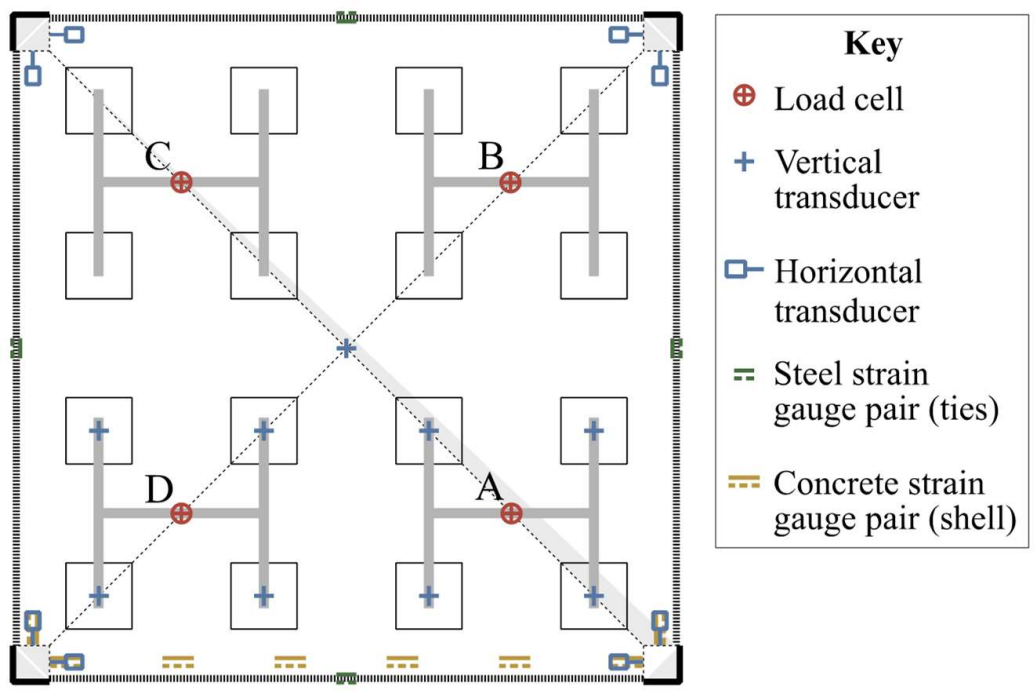

Fig. 8 Instrumentation set-up showing arrangement of loadcells, transducers and strain gauges for both specimens

Each shell was subject to five test phases, as summarised in Fig. 9. In the first phase, a uniform load was applied up to the minimum design load. The pre-strain was then applied in the second phase by tightening the tie bolts. The third and fourth phases involved a uniform loading and unloading, peaking at the maximum design load. In the fifth and final phase, the load was increased over jacks $\mathrm{C}$ and D (to failure) whilst being held constant in jacks A and B, thus simulating an asymmetric live load. 


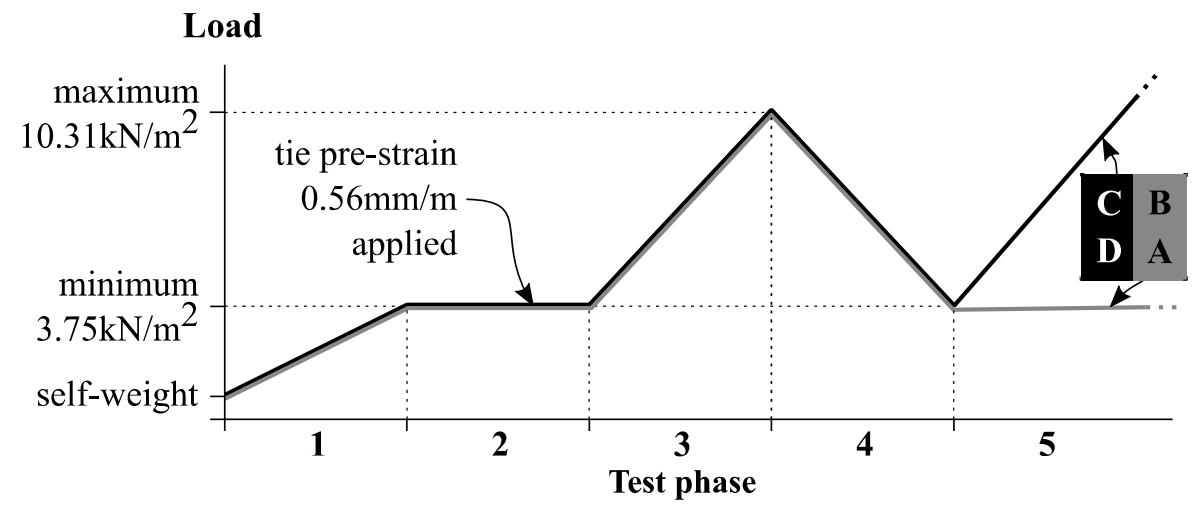

Fig. 9 Both shells were subject to five phases of load testing. In the final phase, an asymmetric load was increased to failure.

\section{Results}

Both shells were tested fourteen days after casting. Fig. 10 gives a summary of the loaddeformation results from each test, highlighting the five test phases. The deformations shown are relative to the start of the test, and the total loads include the self-weight of the spreader assembly $(0.41 \mathrm{kPa})$ and the specimens themselves $(0.41 \mathrm{kPa}$ and $0.79 \mathrm{kPa}$ for the unfilled and filled shells respectively).
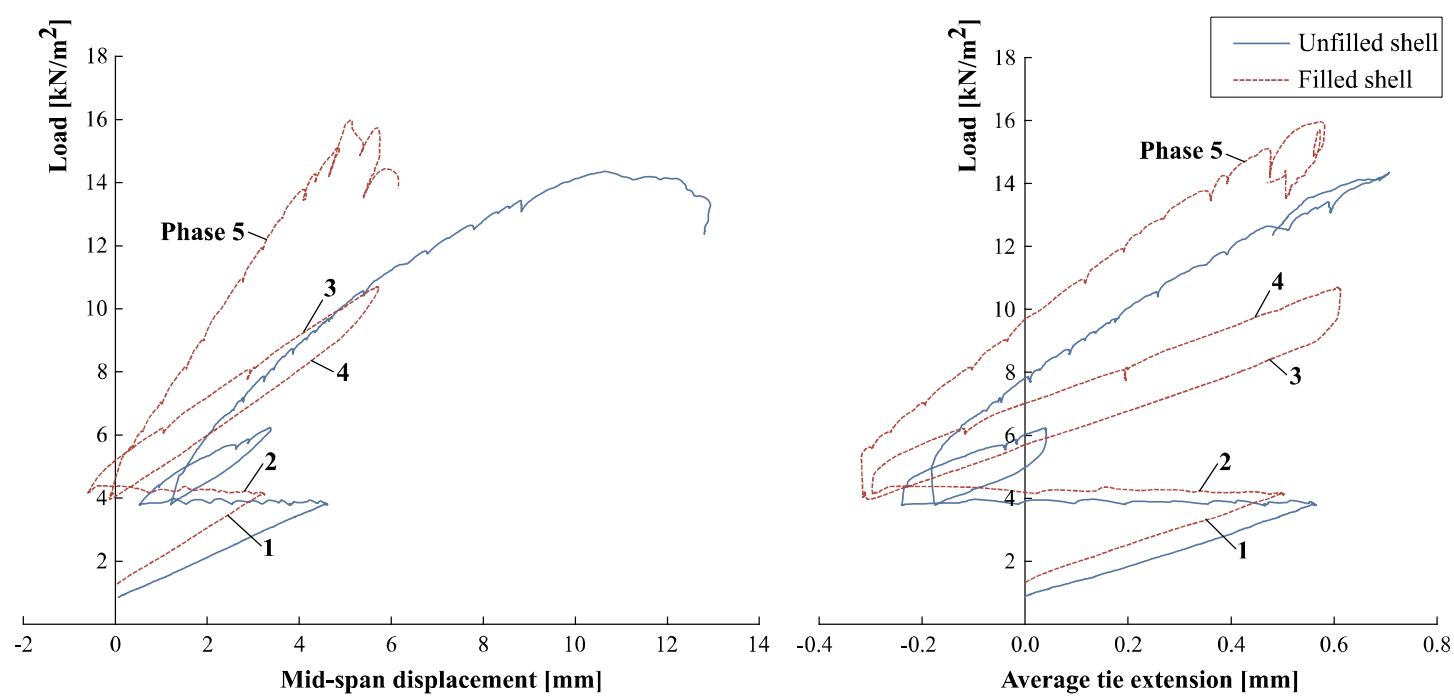

Fig. 10 Overview of load-displacement behaviour of the unfilled and filed shells. The left graph shows the (vertical) mid-span displacement over the full five test phases and the right graph shows the average (horizontal) tie extension.

\subsection{Unfilled shell}

The first phase of loading showed linear deformation behaviour up to a mid-span vertical deflection of 4.6mm (Fig. 10, left) and average tie extension of $0.56 \mathrm{~mm}$ (Fig. 10, right). No 
visible signs of damage were observed. The pre-strain was then applied, reducing the average tie extension by $0.80 \mathrm{~mm}$ and increasing the average tie force by $2.0 \mathrm{kN}$. As the loading was increased in Phase 3, spalling of the bottom cover layer began to occur near to the corner supports. This was caused by poor bonding between the first and second concrete layers. Because of this, it was decided to begin unloading at approximately $6.2 \mathrm{kPa}$ (rather than at the design load of $10.3 \mathrm{kN}$ as planned) in case premature failure prevented the later phases of the test being carried out. A permanent increase in mid-span deflection during the loading and unloading cycle of test Phases 3 and 4 of $0.68 \mathrm{~mm}$ was measured, indicating settling of the supports or potentially damage to the shell. Some hysteresis can also be seen in the tie extension data during these loading phases, possibly caused by friction preventing free horizontal sliding of the supports.

The maximum asymmetric loading reached, including the self-weight, was $14.6 \mathrm{kN} / \mathrm{m}^{2}$. This indicates that, had the uniform loading applied in phase 3 been increased to the intended value, the shell would likely have not failed locally at the corners.

Cracking during the final asymmetric loading phase was readily observable for the unfilled shell. Cracks first appeared along the underside of the shell at a load of approximately $7.2 \mathrm{kPa}$, thus indicating the likely strength of the shell without reinforcement. These cracks developed into a single hinge, with some delamination of the bottom cover layer. A neighbouring hogging region also emerged with a more distributed region of cracking, as can be seen in Fig. 11(a). There was also evidence of cracking at the corners as the loading increased. This is strongly suggestive of the formation of a hinged collapse mechanism, with approximately linear regions of sagging and hogging along the centre of the shell combined with localised rotation at the corners creating a four-hinged mechanism.

The extension of the jacks was continued beyond the peak load, resulting in large vertical deformations of up to $42 \mathrm{~mm}$ (downwards) and $15 \mathrm{~mm}$ (upwards) when the test was stopped. Despite extensive cracking and deformation, the structure did not fail catastrophically and retained a load of approximately $7 \mathrm{kPa}$. The large rotations, extensive cracking and lack of sudden failure each suggest that the primary action causing failure is bending rather than compression which would be expected to exhibit a more sudden, explosive failure.

\subsection{Filled shell}

In the first loading phase the vertical stiffness of the filled shell was noticeably higher than the unfilled shell; rising linearly to $3.24 \mathrm{~mm}$ at mid-span. An analysis of the gradient of these curves 
suggests an increase in stiffness of $37 \%$ compared to the unfilled shell. However, the horizontal stiffness was similar to the filled shell with a comparable average tie extension of $0.50 \mathrm{~mm}$ at the end of Phase 1 . The change in tie extension during Phase 2 was identical to the unfilled shell at $0.80 \mathrm{~mm}$, although the increase in tie force was slightly lower at $1.79 \mathrm{kN}$. In Phase 3 , the uniform load was increased to a peak of $10.7 \mathrm{kPa}$. Delamination of the bottom cover layer was avoided in this phase due to improvements made to the manufacturing method (after observing the unfilled shell test). However, some separation of the TRC shell and foamed concrete fill was visible near the supports at the maximum uniform load. Again, some hysteresis was observed in both the mid-span deflection and average tie extension upon unloading (Phase 4).

In the final asymmetric loading phase, the structural response was again linear until first cracking. This appeared in the foamed concrete fill around the hogging region at approximately $13.4 \mathrm{kPa}$. A similar pattern of cracking to the unfilled shell was observed, with the formation of distinct sagging and hogging hinges across the centre of the shell. As the deformation increased, the TRC and foamed concrete began to separate at the interface (Fig. 11(d)).

The maximum asymmetric load for the unfilled shell was $16.2 \mathrm{kPa}$ including the self-weight; $11.5 \%$ greater than the unfilled shell. However, it is not immediately clear whether this is a result of increased concrete strength, improved manufacturing, variation in geometry or the fill itself. This is explored in the subsequent FE analysis.

Large curvatures were observed at the maximum load, along with separation of the foamed concrete and TRC (Fig. 11d). The test was stopped when the uplift beneath loading jack B reached its physical limit, with maximum recorded upward and downward displacements of $13 \mathrm{~mm}$ and $25 \mathrm{~mm}$ respectively measured at the loading patches. Again, catastrophic failure did not occur, and a load of approximately $10 \mathrm{kPa}$ was retained despite the large deformations. 

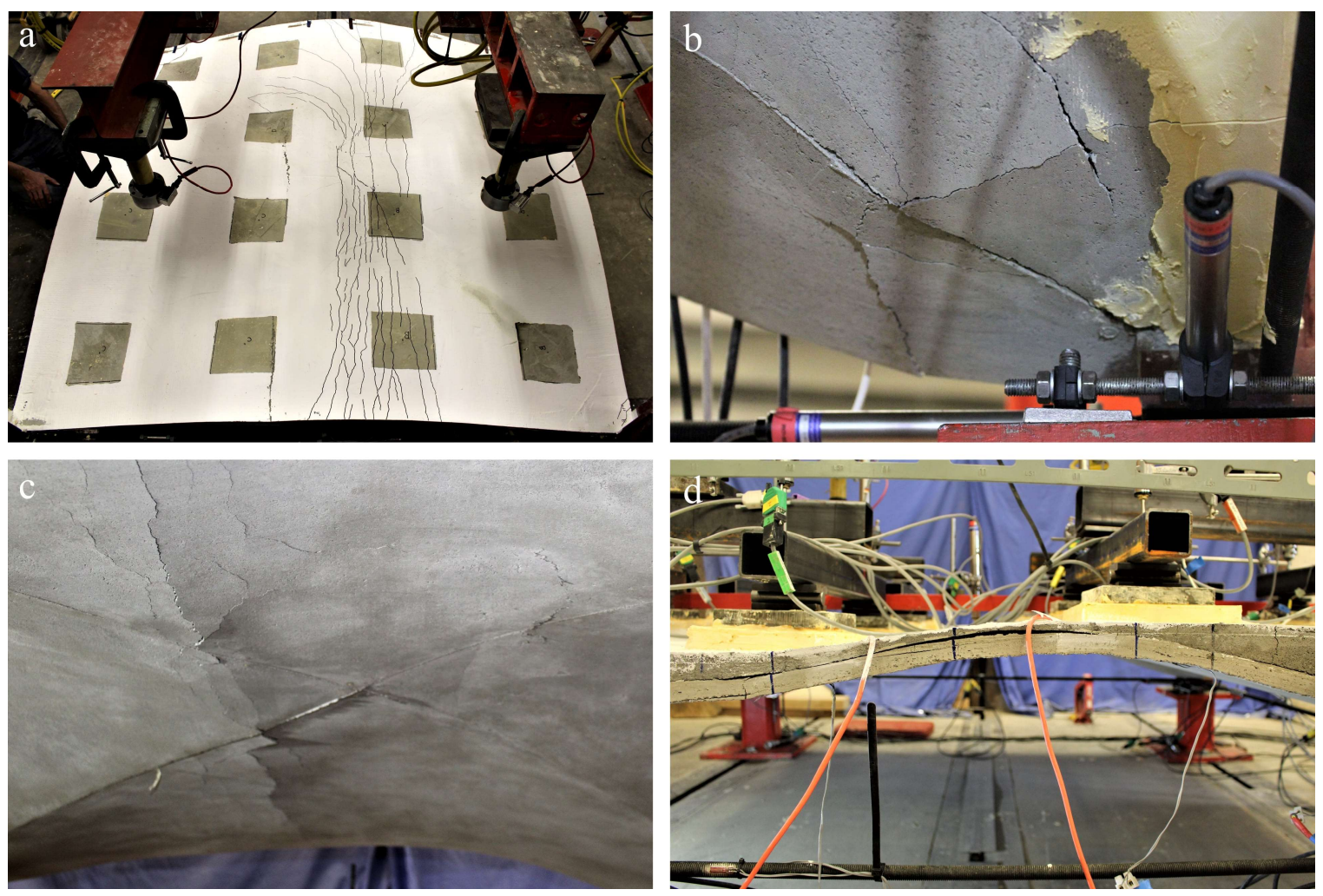

Fig. 11 Deformation of the shells at the ultimate asymmetric load, showing a) hogging cracks in the midportion of the unfilled shell, b) sagging cracks and delamination at corner $\mathrm{C}$ of the unfilled shell, c) sagging cracks on the underside of the filled shell and d) large curvatures and debonding of the fill in the testing of the filled shell. For both shells, similar hinge mechanisms were formed.

\section{Analysis}

The ultimate asymmetric loads carried by the filled (14.6kPa) and unfilled (16.2kPa) shells were greater than the design strength $(10.3 \mathrm{kPa})$ by $41 \%$ and $58 \%$ respectively. This discrepancy might be expected, since the design methodology featured several conservative assumptions including the use of partial material factors and a low estimate of concrete strength. The strength assessment approach used has also been shown by the authors to be conservative under certain loading conditions [27]. A thorough assessment of TRC strength design methods is, however, beyond the scope of this paper. Instead, a non-linear FE analysis model was developed in order to explore and compare in detail the behaviour observed in the two tests.

Not only did the two shells differ by the presence of the foamed concrete fill, as intended, but the filled shell also featured higher strength concrete and was constructed with better bonding between layers than the unfilled shell. Differences in the constructed geometry were also expected. Consequently, isolating the causes of the differences in strength and stiffness measured during testing required a detailed analysis. 


\subsection{Geometry measurement}

Although care had been taken to construct both the formwork and the TRC accurately, construction by hand can lead to manufacturing errors. To quantify this and assess the impact on structural performance, the geometry of each specimen was measured using an Artec 3D 'Eva' digital scanner [37]. To determine both the shell thickness and mid-surface geometry, both the top and bottom surfaces of the shell were measured. It was not however possible to scan the underside of the shell directly after formwork removal due to space restrictions, and therefore the geometry of the underside of the shell was assumed to be similar to that of the formwork, which was scanned prior to casting. Any deformation of the formwork during casting is therefore ignored.

The scans of the formwork and top shell surfaces were then aligned to each other in a registration process. The scanned formwork mesh (bottom shell surface) was firstly positioned using a genetic algorithm to set the six transformations (three translations and three rotations in the $\mathrm{X}, \mathrm{Y}$ and $\mathrm{Z}$ axes) to minimise the average error to the formwork design geometry. The scan of the top surface was then registered using the corner supports as a reference, since these remained fixed throughout construction. The average distances between four matching surfaces on each corner support were minimised to $0.93 \mathrm{~mm}$ and $1.04 \mathrm{~mm}$ for the unfilled and filled shells respectively, thus giving an indication of the likely magnitude of errors in the measured data.

Fig. 12 shows the thickness of each shell and compares the mid-surfaces to the designed geometry. The calculated average thicknesses were $20.4 \mathrm{~mm}$ (standard deviation $2.9 \mathrm{~mm}$ ) and $18.6 \mathrm{~mm}$ (standard deviation $2.7 \mathrm{~mm}$ ) for the unfilled and filled shells respectively. Both shells show areas of higher thickness in the corners and along the diagonal creases, a natural result of smoothing of the concrete around abrupt changes in geometry. Some regions were measured up to $30 \mathrm{~mm}$ thick, significantly greater than the design thickness of $18 \mathrm{~mm}$.

The error in the mid-surface of the shell arises due to deviations both in the thickness and the formwork geometry. The latter might be expected to be similar for both shells since the same formwork was used. Regions near the shell edge, where the centreline is up to 8mm below the design geometry, are likely caused by errors in the formwork geometry, whilst the higher regions along the diagonals are likely a combination of both the formwork errors and increased thickness.

The scanned geometry was later incorporated into an FE model, allowing the structural effects of these geometric imperfections to be investigated. 


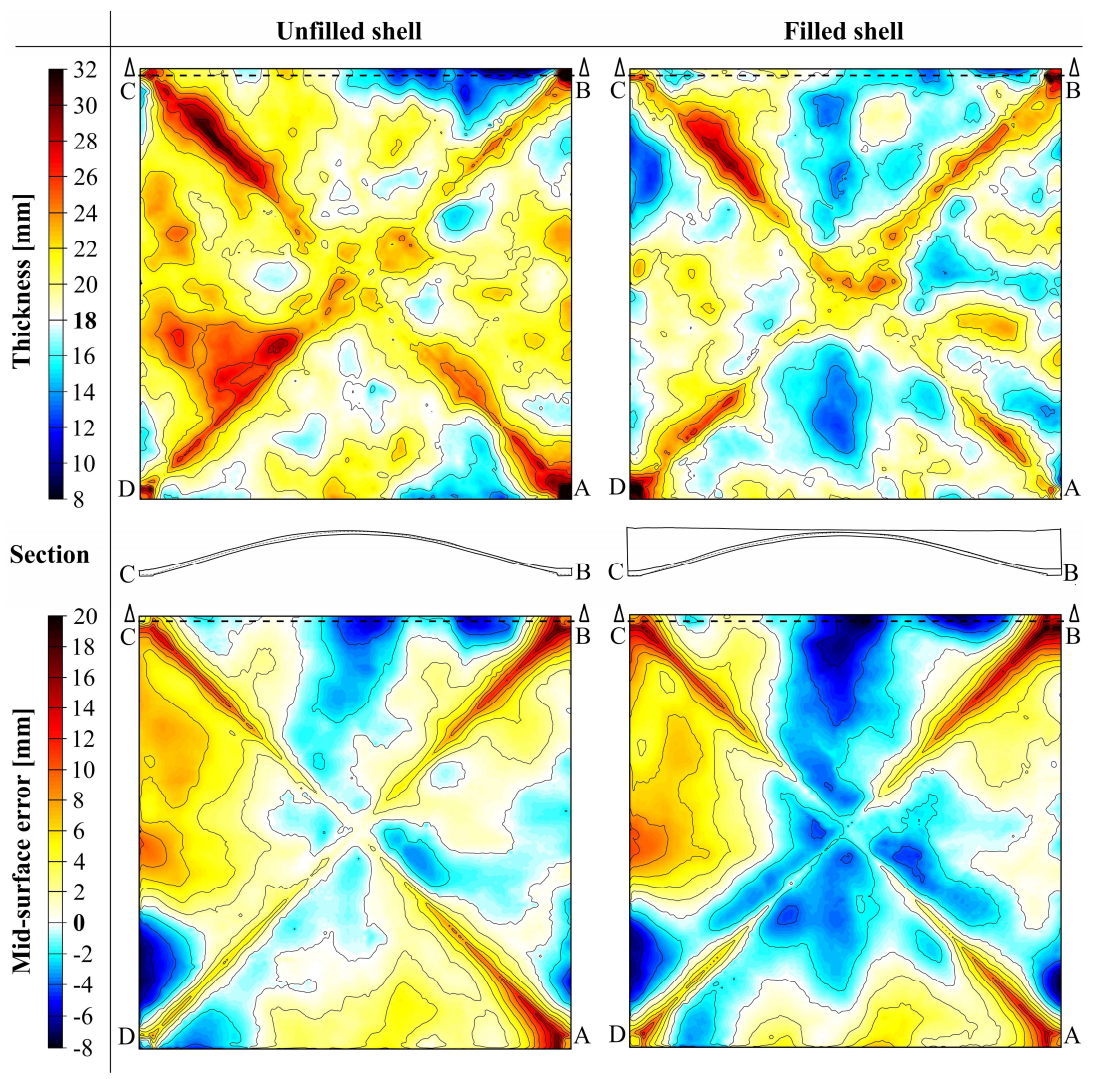

Fig. 12 Maps of thickness and mid-surface error generated from digital scans of formwork and shell surfaces. A section through each shell along the edge B-C is also shown.

\subsection{Modelling methodology}

A finite element model was developed with the aim of investigating the behaviour observed in the tests. The approach taken was to attempt to simulate the shell tests as closely as possible using the available data. The model was created and analysed using the FE modelling software SOFiSTiK [38].

The shell was modelled using quadrilateral (QUAD) elements, each with four nodes. These 2D elements use discreet layers to model the composite behaviour of the concrete and reinforcement, including cracking and anisotropy. Where it was included, the foamed concrete was modelled as a solid using tetrahedral elements.

The steel ties were modelled as linear elements, with the tie stiffness of $13.7 \mathrm{kN} / \mathrm{mm}$ determined from tensile tests on the ties, performed separately. The shell elements within the corner support area were fixed in the vertical direction. The outside edges of each corner support were coupled to each other, simulating a rigid corner support which is free to slide in the $\mathrm{X}$ and $\mathrm{Y}$ directions. 
The self-weight was included based on the measured densities of the TRC and foamed concrete. With the fill included in the model, the shell and solid elements overlap and the TRC density was correspondingly modified to give the correct total self-weight. The jack loads were applied over $200 \mathrm{~mm}$ square patches, matching the test setup. However, the stiffness of the loading plates and plaster was ignored. The models were subject to the same loading sequence as in the physical tests.

The geometric data from the shell scans was imported into the model by modifying the node locations and individual element thicknesses of the 'as-designed' FE mesh. A uniform top and bottom cover to reinforcement of $3 \mathrm{~mm}$ was assumed throughout despite the variable thickness. This modified mesh was then exported back into SOFiSTiK for analysis. The resulting mesh for the unfilled shell is shown in Fig. 13, and contains 1906 quadrilateral elements. An investigation confirmed that increasing the mesh density had no significant impact on the results.

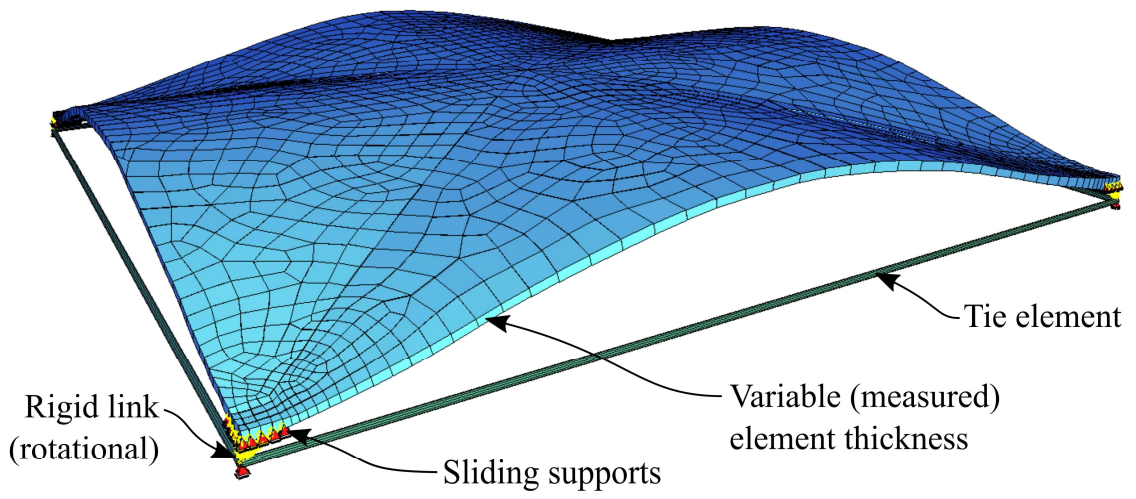

Fig. 13 Undeformed FE mesh of scanned shell geometry used for analysis (unfilled shell), showing variable element thickness.

\subsection{Materials}

Stress-strain curves were defined manually for the fine-grained concrete, textile reinforcement and foam. Measured values of strength were used for an accurate simulation of the tests.

A parabolic stress-strain model was used for the fine-grained concrete, as defined by the concrete compressive strength $f_{c m}$ according to BS EN 1992-1-1 (Table 3.1) [34], albeit with the stiffness reduced by $16 \%$ in accordance with the prism test results described in Section 4.2. The flexural strength $f_{c t m}$ was increased by a factor of 1.58 (accounting for size effects) according to BS EN 1992-1-1 (Equation 3.23) [34], giving tensile strengths of 5.08MPa and 5.33MPa for the unfilled and filled shells respectively. These compare to an average value of 
6.76MPa (at first cracking) determined in four-point bending tests on TRC specimens cast alongside each shell.

The textile reinforcement was modelled as linear elastic up to the failure stress $f_{t c}$, with distinct properties in each direction according to Table 1.

The foam concrete was modelled as linear-elastic in compression with a stiffness of $0.238 \mathrm{GPa}$ up to a strength of $0.83 \mathrm{MPa}$, after which crushing at a constant stress was assumed as observed in the cube tests (Section 4.3) and is typical in brittle foams [36]. The assumed flexural strength of $0.18 \mathrm{MPa}$ was taken as 0.22 times the compressive strength, in accordance with the European Standard for aerated concrete, DIN EN 12602 [39]. This is a conservative ratio according to Valore [40]. A Poisson's ratio of 0.33 was assumed, as is common for closed-cell foams [36].

\subsection{Results and discussion}

Firstly, a model was run with fine-grained concrete strength matching that measured for the unfilled shell (35.5MPa), with the as-designed shell geometry and uniform thickness. A uniform load was applied up to $10.31 \mathrm{kPa}$ (test phase 3) without failure occurring. In the asymmetric phase, cracking was first observed at around 8kPa. The FE model became nonconvergent at a load of $12.0 \mathrm{kPa}$ (18\% lower than the measured strength), at which point the concrete near the corner suppers at $\mathrm{C}$ and $\mathrm{D}$ reached the maximum compressive stress of $35.5 \mathrm{MPa}$. This crushing of the concrete is a result of local stress concentrations at the inner edge of the corner support. In the physical specimens, these stress peaks are likely to have been 'damped' by non-rigid supports and local stress redistribution, leading to a greater ultimate strength.

Fig. 14 shows the maximum stress in the reinforcement (top or bottom) at the maximum asymmetric load. The reinforcement stress is very small (below $25 \mathrm{MPa}$ ) except where cracking has taken place. The figure highlights the cracking pattern, which matches closely that observed in the physical tests. The deformed shape is also similar. The maximum reinforcement stress of $447 \mathrm{MPa}$ is significantly lower than the strength (Table 1), indicating spare capacity in the reinforcement. However, the AR-glass fibre reinforcement gives the thin TRC section a large rotation capacity, which enabled the collapse mechanism and large deformations observed at the end of the physical tests to occur without catastrophic failure. 




Fig. 14 Maximum reinforcement stress (top or bottom) at an asymmetric load of $11.95 \mathrm{kPa}$ measured from the non-linear FE analysis, highlighting cracking pattern. The calculated deformation is also shown (amplified 50 times).

The same model was re-run, this time with the concrete parameters for the filled shell (an increase in concrete strength of $9.8 \%$ ). The same as-designed shell geometry and exclusion of the fill was maintained. The calculated failure load increased by only $0.4 \%$, and the predicted cause of failure was also crushing of the concrete at the supports $\mathrm{C}$ and $\mathrm{D}$. The low sensitivity of the ultimate load to the concrete strength suggests a rapidly increasing maximum concrete stress after the formation of cracks, and suggests that the increased concrete strength was not the cause of the higher strength of the filled shell.

Next, the fill was added to the model. The predicted failure load increased by $25 \%$ to $15.1 \mathrm{kPa}$ (7\% lower than the measured strength) and the stiffness in Phase 1 increased by $7 \%$ compared to the equivalent model with no fill. The maximum compressive stress in the foamed concrete was $0.68 \mathrm{MPa}$, therefore avoiding crushing. The debonding of the fill and the shell (as observed in the tests) did not occur, and therefore the apparently significant strength contribution of the fill may have been over-estimated.

Finally, the effect of the geometric imperfections was investigated by comparing the behaviour with designed geometry to that measured. For the unfilled shell, the original model (with fill excluded) was re-run with the measured shell geometry and thicknesses. The failure load reduced from $12.0 \mathrm{kPa}$ to $11.9 \mathrm{kPa}$. This is a reduction of $0.4 \%$ despite the increased average thickness of $20.4 \mathrm{~mm}$. For the filled shell, the failure load reduced by $1.0 \%$ to $14.9 \mathrm{kPa}$. It may be concluded therefore that the geometric imperfections are likely to have had a negative, albeit small, impact on the strength of the specimens.

Fig. 15 compares the predicted and measured deflections at each loading phase for the two tests, based on the results of the final analysis models with the measured geometry. The patterns 
of vertical displacement measured are similar to those predicted. However, in some cases the magnitudes of the measured displacements are higher. This is particularly evident in Phase 1, and may be a result of deformation and bedding-in of the load spreader assemblies and supporting structures which were not accounted for in the model. There is some variation in the measured tie extensions, likely caused by sticking and slipping of the supports and the low magnitude of the displacements. Nevertheless, the average values agree well with the analysis model. The tie forces measured from strain gauges also corresponded closely to the FEA model. At the ultimate asymmetric load (Fig. 15, Phase 5) the FE model does not predict the large displacements measured since local concrete crushing at the corners causes nonconvergence before these occur.

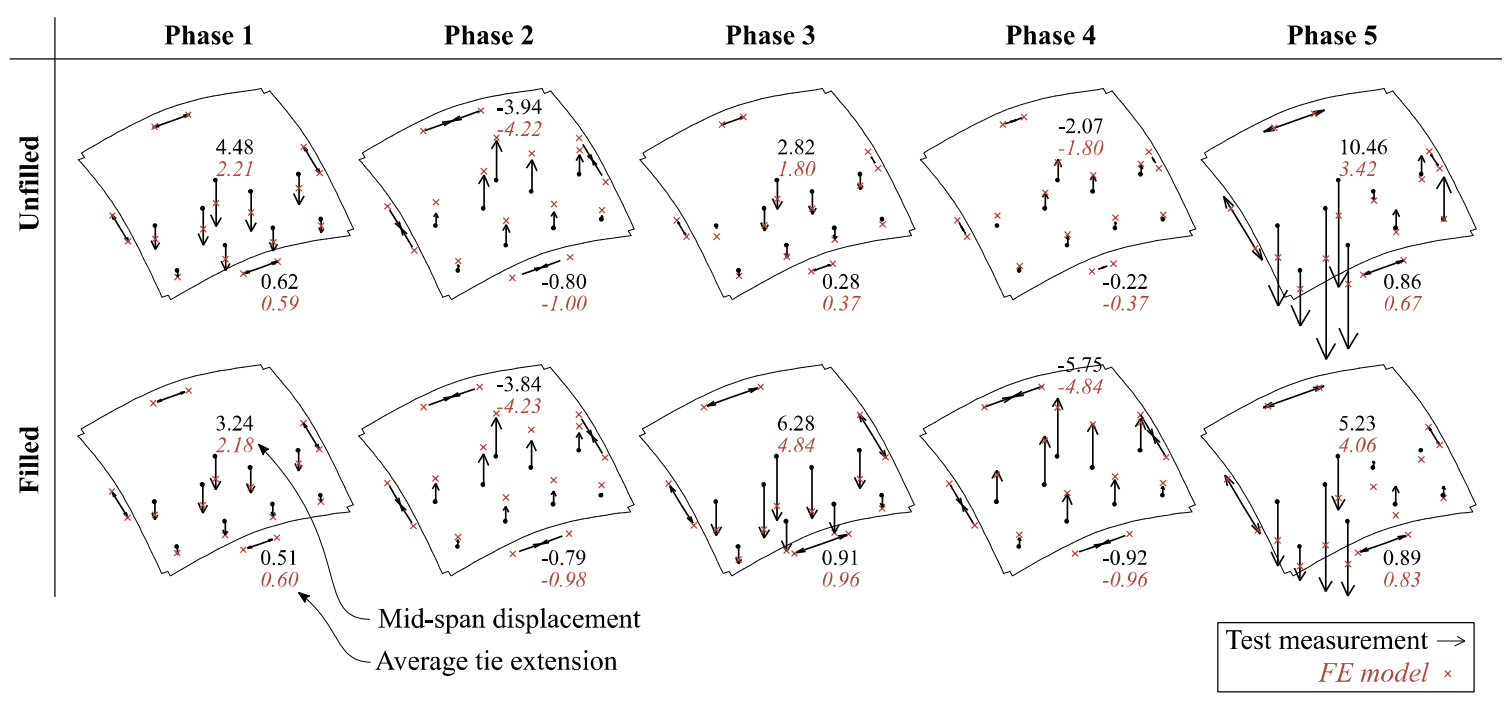

Fig. 15 Comparison of measured and predicted (FE model) incremental displacements for each loading phase.

\section{Conclusions}

This paper has described a series of tests investigating the behaviour of a novel thin-shell TRC flooring system for multi-storey buildings, with potentially less than half the weight and embodied energy of equivalent strength concrete flat slabs [22]. The design, construction, testing and analysis of two quarter-scale specimens is described, each $18 \mathrm{~mm}$ thick and spanning $2 \mathrm{~m}$ with two layers of AR-glass textile reinforcement. These were designed to be identical to each other aside from the presence of the foamed concrete fill, however differences in concrete strength and shell geometry were also noted. 
Physical structural tests were carried out with multiple phases, including uniform loading, prestressing of tie rods and finally asymmetric loading to determine the ultimate strength. In both cases the design strength was exceeded. The ultimate capacity of the filled shell was $11.5 \%$ greater than the unfilled shell, and the stiffness was also increased. Both shells failed in a similar manner, which involved the development of distinct regions of high curvature and cracking. This led to the formation of a collapse mechanism and subsequent decline in load capacity. The AR-glass fibre textile reinforcement enabled large deformations to occur without catastrophic failure, suggesting that similar structures would be robust in the event of accidental over-loading.

A non-linear FE analysis model was developed incorporating material models calibrated from physical tests. A similar pattern of cracking behaviour and deformation was replicated in the FE analysis, which moderately under-estimated the ultimate strength for both tests specimens. The as-built geometry of the shells was measured using a digital 3D scanner and analysed in the FE model. The analysis results suggest that the presence of the foamed concrete fill was the likely cause of the difference in strength between the two specimens tested, rather than variations in geometry or concrete strength.

\section{Future work}

An alternative analysis approach to that described in Section 8, based on a linear FE analysis in combination with a TRC failure envelope, was used in the design of the shells. This method is proposed by Scholzen et al. [33] and has been extended by the authors [27, 22]. The effectiveness of this method has not been assessed in detail in this paper, however the results provide an opportunity to do this. A comparison between the various approaches will be made in order to evaluate their relative merits and applications.

Vibration often governs the design of lightweight floor structures, particularly for longer spans, but has not yet been considered in detail for the proposed system.

Further consideration of manufacturing methods will also be given, including the potential for automated placement of both concrete and reinforcement. Automated manufacturing allows 'mass customisation' of precast elements, enabling greater architectural flexibility and structural efficiency. Reductions in construction tolerance, time and cost could also be expected. Furthermore, the thickness of the shell and placement of the reinforcement could be optimised without additional manufacturing complexity, leading to further potential material 
savings. Alternative formwork strategies, including inflatable membranes or formless construction methods [41], could also be investigated.

This investigation has demonstrated the high structural efficiency, construction feasibility and robustness of the proposed flooring system, and has verified an FE modelling approach. This supports the next phase of this research, in which detailed design case-studies representing realworld use will be carried out. The complexities of stability loads, service openings and irregular floorplans will also be considered, allowing the environmental advantages of the system to be assessed in detail.

\section{Acknowledgements and data access}

The authors would like to thank the technicians of the Department of Architecture and Civil Engineering, University of Bath, particularly Miles Chambers (formwork construction), Ian Benford (shell construction) and Will Bazeley (instrumentation and testing). This research is supported by the EPSRC Centre for Decarbonisation of the Built Environment (dCarb) [grant number EP/L016869/1], the Building Research Establishment (BRE) Trust and the Cambridge University Department of Engineering. Additional support was provided through EPSRC grant number EP/M020908/2. All data created in this research are openly available from the University of Cambridge data repository at https://doi.org/10.17863/CAM.26103. 


\section{References}

1. Abergel T, Dean B, Dulac J (2017) Towards a zero-emission, efficient, and resilient buildings and construction sector: Global Status Report 2017. UN Environment and International Energy Agency.

2. Krausmann F, Wiedenhofer D, Lauk C, Haas W, Tanikawa H, Fishman T, Miatto A, Schandl H, Haberl H (2017) Global socioeconomic material stocks rise 23-fold over the 20 th century and require half of annual resource use. Proceedings of the National Academy of Sciences. doi:10.1073/pnas. 1613773114

3. Orr JJ, Darby AP, Ibell TJ, Evernden MC, Otlet M (2011) Concrete structures using fabric formwork. The Structural Engineer 89 (8):20-26

4. Moynihan MC, Allwood JM (2014) Utilization of structural steel in buildings. Proceedings of the Royal Society of London A: mathematical, physical and engineering sciences 470 (2168):20140170-20140170

5. Orr J, Bras A, Ibell T (2017) Effectiveness of design codes for life cycle energy optimisation. Energy and Buildings 140:61-67. doi:https://doi.org/10.1016/j.enbuild.2017.01.085

6. Foraboschi P, Mercanzin M, Trabucco D (2014) Sustainable structural design of tall buildings based on embodied energy. Energy and Buildings 68:254-269

7. De Wolf C, Ramage M, Ochsendorf J (2016) Low Carbon Vaulted Masonry Structures. Paper presented at the IASS Annual Symposium, Tokyo, September 2016.

8. Boden T, Andres R, Marland G (2017) Global CO2 Emissions from Fossil-Fuel Burning, Cement Manufacture, and Gas Flaring: 1751-2014. Oak Ridge National Laboratory, Available at: http://cdiac.ess-dive.lbl.gov/ftp/ndp030/global.1751_2014.ems

9. Isler H (1994) Concrete shells derived from experimental shapes. Structural Engineering International 4 (3):142-147

10. Ockleston A (1958) Arching action in reinforced concrete slabs. The Structural Engineer $36(6): 197-201$

11. Bannister TC (1968) The Roussillon Vault: The Apotheosis of a" Folk" Construction. Journal of the Society of Architectural Historians 27 (3):163-175

12. Collins GR (1968) The transfer of thin masonry vaulting from Spain to America. Journal of the Society of Architectural Historians 27 (3):176-201

13. Tully DF (1979) Inverted, doubly-curved umbrella, hyperbolic paraboloid shells with structurally integrated upper diaphragm. U.S. Pat no. US4137679 A, February 1979

14. Leggatt A (1980) GRC and other laminar concrete. In: Neville AM, Chatterton M (eds) New concrete technologies and building design. Wiley, New York.

15. Ramaswamy GS, Chetty SMK (1960) A New Form of Doubly Curved Shell for Roofs and Floors. International Association for Shell Structures 1:49-56

16. Liew A, López DL, Van Mele T, Block P (2017) Design, fabrication and testing of a prototype, thin-vaulted, unreinforced concrete floor. Engineering Structures 137:323-335. doi:10.1016/j.engstruct.2017.01.075

17. West M (2003) Fabric-formed concrete members. Concrete international 25 (10):55-60

18. Zhang Z, Provis JL, Reid A, Wang H (2015) Mechanical, thermal insulation, thermal resistance and acoustic absorption properties of geopolymer foam concrete. Cement and Concrete Composites 62:97-105. doi:10.1016/j.cemconcomp.2015.03.013

19. Lichtenberg J, Pronk A (2002) Sandwich flooring. Pat no. NL1018156, December 2002 
20. Nguyen VA, Jesse F, Curbach M (2016) Experiments to establish the loadbearing behaviour of lightweight sandwich beams using textile-reinforced and expanded polystyrene concrete. Structural Concrete 17 (5):760-767. doi:10.1002/suco.201500156

21. Triantafillou $T$ (2016) Textile Fibre Composites in Civil Engineering. Woodhead Publishing. doi:10.1016/C2014-0-01415-3

22. Hawkins W, Orr J, Shepherd P, Ibell T, Bregulla J (2017) Thin-shell textile-reinforced concrete floors for sustainable buildings. Paper presented at the IASS Annual Symposium, Hamburg, September 2017.

23. British Standards Institution (2002) Eurocode 1: Actions on structures. Part 1-1: General actions - Densities, self-weight, imposed loads for buildings. British Standards Institution, London

24. Preisinger C (2013) Linking structure and parametric geometry. Architectural Design 83 (2): $110-113$

25. Rutten D (2013) Galapagos: On the Logic and Limitations of Generic Solvers. Architectural Design 83 (2):132-135. doi:10.1002/ad.1568

26. Song YS, Youn JR, Gutowski TG (2009) Life cycle energy analysis of fiber-reinforced composites. Composites Part A: Applied Science and Manufacturing 40 (8):1257-1265

27. Hawkins W, Orr J, Ibell T, Shepherd P (2018) An Analytical Failure Envelope for the Design of Textile Reinforced Concrete Shells. Structures 15:56-65. doi:10.1016/j.istruc.2018.06.001

28. Ohno S, Hannant D (1994) Modelling the stress-strain response of continuous fiber reinforced cement composites. ACI Materials Journal 91 (3):306-312

29. Butler M, Mechtcherine V, Hempel S (2010) Durability of textile reinforced concrete made with AR glass fibre: effect of the matrix composition. Materials and structures 43 (10):1351-1368. doi:10.1617/s11527-010-9586-8

30. Orlowsky J, Raupach M (2008) Durability model for AR-glass fibres in textile reinforced concrete. Materials and Structures 41 (7):1225-1233. doi:10.1617/s11527-007-9321-2

31. British Standards Institution (2012) Fly ash for concrete. Definition, specifications and conformity criteria, BS EN 450-1:2012. BS EN 450-1:2012. British Standards Institution, London

32. Verwimp E, Tysmans T, Mollaert M, Berg S (2015) Experimental and numerical buckling analysis of a thin TRC dome. Thin-Walled Structures 94:89-97. doi:10.1016/j.tws.2015.03.021

33. Scholzen A, Chudoba R, Hegger J (2015) Thin-walled shell structures made of textilereinforced concrete: Part II. Structural Concrete 16 (1):115-124. doi:10.1002/suco.201400046

34. British Standards Institution (2004) Eurocode 2: Design of concrete structures. Part 1-1: General rules and rules for buildings. British Standards Institution, London

35. EABASSOC (2018) EABASSOC Foaming Agent for lightweight foamed concrete production. Available at: https://www.eabassoc.co.uk/datasheets/EABASSOC-ConcreteFoaming-Agent.pdf.

36. Gibson LJ, Ashby MF (1999) Cellular solids: structure and properties. Cambridge University Press, UK. doi:10.1017/CBO9781139878326

37. Artec Group (2015). http://www.artec3d.com/hardware/artec-eva.

38. SOFiSTiK (2016) SOFiSTiK-Finite Element Software.

39. Deutsches Institut für Normung e. V. (2016) DIN EN 12602: Prefabricated reinforced components of autoclaved aerated concrete. DIN EN 12602. 
40. Valore RC (1954) Cellular Concretes: Part 2, Physical Properties. Journal of the American Concrete Institute 50 (10):817-836. doi:10.14359/11795

41. Neudecker S, Bruns C, Gerbers R, Heyn J, Dietrich F, Dröder K, Raatz A, Kloft H (2016) A new robotic spray technology for generative manufacturing of complex concrete structures without formwork. Procedia CIRP 43:333-338 